\title{
UMA RESPOSTA POLÍTICA PARA A FOME: JOSUÉ DE CASTRO E AS LIGAS CAMPONESAS
}

\section{José Raimundo Sousa Ribeiro Junior}

Universidade Federal de São Paulo

Resumo: Este artigo tem como objetivo analisar o posicionamento político e a perspectiva teórico-metodológica que fundamentam o livro Sete Palmos de Terra e um Caixão, escrito por Josué de Castro às vésperas do Golpe de 10 de abril de 1964. Após a apresentação do contexto nacional e internacional em que o livro foi escrito, localizo o livro dentro do movimento da obra do autor. Em seguida, examino como o autor procura desmistificar o surgimento e a atuação das Ligas Camponesas e interpreto a perspectiva teórico-metodológica que fundamenta o trabalho do autor. Por fim, argumento que esse livro traz contribuições imprescindiveis para que possamos pensar formas de superar a fome nos dias de hoje. Entre elas destacam-se a crítica às soluções tecnicistas para os problemas sociais e a compreensão de que aqueles que convivem com a fome são sujeitos políticos que têm condições de se organizar e transformar suas próprias condições de vida. Palavras chave: Josué de Castro. Sete Palmos de Terra e um Caixão. Fome. Ligas Camponesas. Reforma Agrária.

\section{A POLITICAL RESPONSE TO HUNGER: JOSUÉ DE CASTRO AND THE PEASANT LEAGUES}

Abstract:TIn this article I analyze the political position and the theoretical-methodological perspective that underlie the book Six Feet Under and a Coffin written by Josué de Castro on the eve of the 1964 coup. First I present the national and international context in which this book was written and situate this book within the movement of the author's work. Thereafter I examine how the author seeks to demystify the emergence and performance of the Peasant Leagues and interpret the theoretical-methodological perspective that underlies the author's work. Finally, I argue that this book brings essential reflections so that we can think of ways to overcome hunger today. Among them are the criticism of technical solutions to the social and the understanding that those who live with hunger are political subjects who are able to organize and transform their own living conditions.

Keywords: Josué de Castro. Six Feet Under and a Coffin. Peasant Leagues. Hunger Land Reform.

\section{UNA RESPUESTA POLÍTICA AL HAMBRE: JOSUÉ DE CASTRO Y LAS LIGAS CAMPESINAS}

Resumen: Este artículo tiene como objetivo analizar la posición política y la perspectiva teórico-metodológica que subyace en el libro Sete Palmos de Terra e um Caixão, escrito por Josué de Castro en vísperas del golpe de Estado del 1 de abril de 1964. Después de presentar el contexto nacional e internacional en el que se escribió el libro, ubico el libro dentro del movimiento de la obra del autor. En luego, examino cómo el autor busca desmitificar el surgimiento y el desempeño de las Ligas Campesinas e interpretar la perspectiva teórica y metodológica que subyace en el trabajo del autor. Por finalmente, sostengo que este libro aporta contribuciones esenciales para que podamos pensar en formas de superar el hambre hoy. Entre ellos, destaca la crítica a las soluciones técnicas. para los problemas sociales y la comprensión de que quienes viven con hambre son sujetos políticos que pueden organizarse y transformar sus propias condiciones de vida. Palabras clave: Josué de Castro. Siete tramos de tierra y un ataúd. Hambre. Ligas campesinas. Reforma agraria. 
Introdução

Escrito entre outubro de 1962 e fevereiro de 1964, período marcado pelas intensas disputas em torno dos rumos políticos, econômicos e sociais do país, Sete Palmos de Terra e um Caixão é uma das últimas e mais importantes publicações de Josué de Castro. Neste livro ele analisa o contexto explosivo em que o Nordeste brasileiro se encontrava antes do golpe de 1964, defende com veemência a necessidade de realização da reforma agrária e evidencia a recusa das elites dirigentes que apoiaram o golpe em aceitar a realização das modificações estruturais necessárias para que os brasileiros pudessem se libertar de sua miséria (CASTRO, 1967).

No início dos anos 1960 não era apenas o contexto político nacional que se encontrava conturbado. A Revolução Cubana teve grande repercussão no cenário político internacional (em especial na América Latina) e foi responsável entre outras coisas, por uma redefinição das prioridades da política externa norte-americana que passou a dedicar maior atenção à América Latina. Frente a uma região que apresentava uma crescente mobilização social, composta por correntes reformistas e revolucionárias que questionavam com maior ou menor radicalidade o subdesenvolvimento e a dependência latino-americana, a estratégia dos Estados Unidos passou a incluir uma série de ações complementares: do programa Aliança para o Progresso ${ }^{1}$, com o pretenso objetivo de acelerar o desenvolvimento econômico dos países latino-americanos e assim diminuir suas convulsões internas, passando pelas habituais pressões diplomáticas e financeiras, até o uso direto e indireto das forças armadas (RAPOPORT e LAUFER, 2000).

Entre os estrategistas norte-americanos ganhava força o entendimento de que os exércitos latinoamericanos deveriam garantir a ordem econômica e social no continente. Assim, a crescente efervescência social latino-americana, entendida "como 'exploração comunista' da crise econômica e do descontentamento social" (RAPOPORT e LAUFER, 2000, p. 71), teve como resposta a adoção generalizada na América Latina (sobretudo nos países do Cone Sul) de uma doutrina militar centrada no combate ao "inimigo interno" que

\footnotetext{
"'Programa de assistência ao desenvolvimento socioeconômico da América Latina formalizado quando os Estados Unidos e 22 outras nações do hemisfério, entre elas o Brasil, assinaram a Carta de Punta del Este em agosto de 1961. De acordo com o documento, os países latino-americanos deveriam traçar planos de desenvolvimento e garantir a maior parte dos custos dos programas, cabendo aos EUA o restante. A administração dos fundos norte-americanos competia em sua maior parte à United States Agency for International Development (USAID - Agência dos Estados Unidos para o Desenvolvimento Internacional). (...) Ao longo de quase dez anos de funcionamento, a Aliança para o Progresso recebeu inúmeras críticas tanto de especialistas, que atacavam as deficiências de sua estrutura e a irrealidade de suas metas, como de setores liberais e de esquerda da opinião pública latino-americana, que a encaravam como instrumento a serviço dos interesses econômicos e estratégicos dos EUA no hemisfério" (ABREU, 2010).
}

justificou, entre outras coisas, a perseguição, tortura e assassinato de militantes de esquerda.

Foi nesse contexto que uma editora norte-americana convidou Josué de Castro a escrever um livro no qual ele explicasse à população daquele país a situação explosiva do Nordeste brasileiro no início dos anos 1960. Para ser mais preciso, o convite tinha como objetivo abrir espaço para uma visão que confrontasse um jornalismo, caracterizado pelo próprio autor, como tendencioso e sensacionalista e que, em consonância com as estratégias da política externa norte-americana, despertava uma preocupação crescente com a propagação do comunismo na América Latina (CASTRO, 1967, p. 33).

Já reconhecido nacional e internacionalmente por conta de seus estudos sobre a fome ${ }^{2}$, assim como por sua destacada atuação política ${ }^{3}$, Josué de Castro aceitou o convite e escreveu um livro que procurava tanto apresentar com profundidade as relações políticas, econômicas e sociais que historicamente caracterizavam a região Nordeste, como explicar o acelerado processo de transformação social pelo qual a região estava passando.

Hoje, mais de 50 anos após sua publicação, Sete Palmos de Terra e um Caixão permanece atual. Nem tanto por conta do contexto nacional e internacional, por mais que a retórica anticomunista tenha ganhado força nos últimos anos, mas pelos desafios que Josué de Castro identificava e buscava superar. Para ele era necessário explicitar quais eram os processos e relações sociais responsáveis pela miséria e pela fome; rechaçar as imagens deturpadas dos movimentos sociais e contrapor-se a criminalização destes; questionar a pretensa neutralidade científica e defender uma ciência que é ao mesmo tempo comprometida e participante; extrapolar os limites disciplinares dentro e fora do ambiente acadêmico e alertar para o perigo das respostas tecnicistas e economicistas em relação aos problemas sociais. Como não reconhecer que estes são, ainda hoje, desafios para aqueles que estão comprometidos com a superação da fome?

Nesse sentido, este artigo tem como objetivo analisar o posicionamento político e a perspectiva teórico-metodológica que fundamentam o livro Sete Palmos de Terra e um Caixão, escrito por Josué de Castro às vésperas do Golpe de $1^{\circ}$ de abril de 1964. Nesse sentido, buscarei destacar as contribuições que

2Para citar apenas alguns livros mais conhecidos: Geografia da Fome, publicado em 1946; Geopolítica da Fome, 1951; O Livro Negro da Fome, 1957

${ }^{3}$ Eleito deputado federal por Pernambuco em 1954 e reeleito em 1958 (nos dois casos pelo Partido Trabalhista Brasileiro), Josué de Castro foi designado em 1962 "pelo então presidente João Goulart, embaixador-chefe da delegação do Brasil junto à ONU, em Genebra" (MELO; NEVES, 2007, p.282). 
este livro apresenta para o debate teórico e político sobre a relação entre a fome e as relações sociais que caracterizam uma estrutura social oligárquica que tem como fundamentos a grande propriedade de terras e a monocultura.

Para isso, a partir daqui divido a exposição em quatro momentos: no primeiro localizo o livro Sete Palmos de Terra e um Caixão no movimento da obra de Josué de Castro, chamando a atenção para as continuidades e descontinuidades que esse livro apresenta em relação aos seus trabalhos anteriores; em seguida, busco explicitar quais eram os objetivos de Josué de Castro ao escrever esse livro e como eles revelam o sentido político que ele atribuía ao seu trabalho acadêmico; no terceiro momento, interpreto a perspectiva teóricometodológica que fundamenta o trabalho do autor; e, nas considerações finais, procuro destacar a pertinência de retomarmos esse livro para enfrentar os obstáculo que ainda hoje se erguem contra aqueles que lutam pela superação da fome.

\section{O livro Sete Palmos de Terra e um Caixão no movimento} da obra de Josué de Castro

Nascido em 1908, Josué de Castro forma-se em Medicina em 1929 na então Universidade do Rio de Janeiro. Logo após concluir o curso retorna ao Recife onde volta a ter contato com a dura realidade de sua cidade natal. 0 retorno produziu grande impacto sobre 0 jovem médico, pois trabalhando em uma grande fábrica constata que os recorrentes problemas de saúde dos trabalhadores que atendia decorriam principalmente de sua má alimentação.

No afã de compreender melhor a situação de vida desses trabalhadores, Josué de Castro se aproximou gradativamente das ciências humanas em um movimento de superação de uma visão estritamente médica dos problemas relativos à alimentação. Nesse processo, a partir da década de 1930 ele passa a redigir importantes trabalhos sobre os problemas relativos à alimentação que culminarão na publicação de Geografia da Fome em 1946, obra que se tornou uma referência para o pensamento social brasileiro.

É importante destacar, que no momento em que se aproximava das Ciências Humanas, elas sequer haviam passado pelo processo de institucionalização no Brasil. Assim, é possível afirmar que ele não apenas foi muito influenciado, como de alguma forma também fez parte do que Antonio Candido (2006, p.271) definiu como "intelectuais não especializados, interessados principalmente em formular princípios teóricos ou interpretar de modo global a sociedade brasileira".

Apesar de se debruçar especificamente sobre o desenvolvimento da Sociologia no Brasil, Antonio Candido aponta para algumas características que podem ser atribuídas a todo pensamento social brasileiro do início do século XX e, assim, nos ajuda a compreender o debate no qual Josué de Castro estava inserido. Para ele, esse é um momento marcado pela preocupação em elaborar "uma 'teoria geral de Brasil' do ponto de vista da sua evolução social e das características organizatórias, com acentuada preferência pelos aspectos políticos" (CANDIDO, 2006, p. 278). Além disso, o esforço de muitos autores naquele período seria marcado pelo "empenho de desvendar necessidades e características nacionais com o fim precípuo de servir ao progresso do país, em relação ao qual se verificava acentuado pessimismo", por vezes com o objetivo de "se apontarem remédios de ordem político-administrativa" (CANDIDO, 2006, p. 279).

É nesse contexto que, a partir dos anos 1930, Josué de Castro busca se inserir em um debate marcado pela publicação de alguns dos mais importantes estudos sobre a formação da sociedade brasileira e que acabaram por constituir aquilo que se denomina como "ensaísmo de interpretação do Brasil"4 (BOTELHO, 2010, p. 48).

Considerando todo o movimento da obra de Josué de Castro, Sete Palmos de Terra e um Caixão apresenta tanto continuidades como descontinuidades em relação aos seus trabalhos anteriores. Em outras palavras, é possível identificar nesse livro momentos em que o autor recorre aos seus estudos anteriores e aprofunda algumas de suas análises sobre a realidade latino-americana, brasileira e em especial do Nordeste brasileiro. Ao mesmo tempo, o livro também apresenta mudanças de rumo em relação a sua trajetória, principalmente no que se refere ao seu posicionamento político e a sua perspectiva teórico-metodológica.

A leitura atenta do conjunto de sua obra revela que ela não é caracterizada pela linearidade, mas por sucessivos redirecionamentos que produzem descontinuidades. Cada publicação (livro, ensaio, artigo etc.) tem um sentido próprio dentro do todo, o que não significa que sua obra seja possa ser qualificada como incoerente ou inconsistente. Pelo contrário, as continuidades e descontinuidades apontam para um pensamento vivo, permeado pelos processos políticos, econômicos e sociais vividos e estudados pelo autor. Pensamento que não pode ser apreendido por leituras que, ao ficarem restritas a momentos ou publicações específicas de

${ }^{4}$ Para citar apenas os mais representativos: Casa grande e Senzala (1933) e Sobrados e mocambos (1936) de Gilberto Freyre, Evolução política do Brasil (1933) e Formação do Brasil contemporâneo (1942) de Caio Prado, Raízes do Brasil (1936) de Sérgio Buarque de Holanda. 
sua obra, tendem a perder de vista esse movimento e a produzir conclusões que imobilizam sua obra.

Um elemento que merece destaque em Sete Palmos de Terra e um Caixão é o esforço de Josué de Castro em "aprofundar ao máximo o seu conhecimento científico do mecanismo destas mudanças [sociais]", uma vez que "os valores mais desejáveis por esta sociedade são os ligados à mudança e não à estabilidade" (CASTRO, 1967, p. 15).

O entendimento de que as mudanças sociais eram desejáveis está em consonância com as transformações que a própria realidade colocava para o autor. O período que vai de meados da década de 1950 até meados da década de 1960 é caracterizado pela intensa efervescência política e social no Nordeste e particularmente em Pernambuco, estado no qual Josué de Castro nasceu e viveu boa parte de sua vida. Em suas próprias palavras, o Nordeste havia se tornado uma área explosiva, "isto é, como uma área onde as tensões sociais, estão alcançando os limites do tolerável - limite em que os conflitos latentes entram em combustão violenta, provocando a explosão social" (CASTRO, 1967, p. 18).

Profundamente interessado e comprometido com as mobilizações sociais que se processavam nessa área, o autor assume uma posição diferente daquela apresentada em obras anteriores ao defender abertamente a necessidade de ruptura com a ordem estabelecida e concluir que "só através de profundas modificações estruturais, que dificilmente serão alcançadas sem violência, poderão estes povos [latinoamericanos] se libertar de sua miséria." (CASTRO, 1967, p. 175).

Este posicionamento destoa, por exemplo, daquele que encontramos em Geografia da Fome. Publicado originalmente em 1946, num contexto marcado pela redemocratização no Brasil e pela derrota do nazifascismo na Europa, esse livro manifestava uma posição otimista com relação aos novos tempos. Tomando as contribuições de Bertrand Russell e de Julian Huxley como referências, Josué de Castro afirma no prefácio de Geografia da Fome que compartilhava "a mesma crença [destes autores] na obra de cooperação de cada um, de coparticipação ativa na busca de um mundo melhor" e entendia que era chegada "a era do homem social, em contraposição a essa outra era que terminou com a Segunda Guerra Mundial, a era do homem econômico" (CASTRO, 1948, p.38).

Essa compreensão ganhou força nas obras subsequentes. Em Geopolítica da Fome (publicado originalmente em 1951) ele caracteriza o mundo do pós-guerra como aquele em que há uma focalização intensiva do homem biológico como entidade social concreta, uma espécie de prioridade dos problemas humanos sobre os problemas econômicos puros. Não quer isso dizer que, nesta nova era do homem social, a economia seja relegada a um plano secundário; é que esta é agora orientada como um fator para a obtenção do bem-estar humano (CASTRO, 1965, p. 53).

Tanto em Geografia como em Geopolítica da Fome, confiava às elites dirigentes a tarefa de resolver os problemas do país. Para ele,

[a] alarmante situação do país em matéria de alimentação para a qual contribuíram todas as forças vivas e todas as classes da nação, exige que as elites dirigentes - o governo, as classes intelectuais e as produtivas - encarem o problema alimentar em sua devida importância, reconhecendo a necessidade urgente de melhorar as condições alimentares do povo brasileiro, entravando a marcha da fome que cada vez mais alarga seus passos, ampliando as suas áreas de devastação e aprofundamento a sua ação maléfica nas primitivas áreas. (CASTRO, 1948, p. 303, grifo nosso).

Em consonância com essa posição, defendia a estruturação de um "plano sistematizado de política alimentar", que deveria ser realizado por "um órgão técnico-administrativo que [unificasse] o problema preconizando medidas articuladas num plano de largo alcance" (CASTRO, 1948, p. 303). Em síntese, a superação da fome passaria por um Estado mais justo, dirigido por uma elite política, intelectual e produtiva, que promovesse uma política alimentar através de preceitos técnico-administrativos.

É importante destacar que os dois últimos trechos citados, presentes nas primeiras edições de Geografia da Fome, não constam das impressões realizadas a partir da $9^{a}$ edição. Sobre essa edição, Josué de Castro afirma que "o livro que ora apresentamos representa uma verdadeira inovação sobre as suas edições anteriores" (CASTRO, 1984, p. 47). E, mais adiante, de maneira bastante distinta das primeiras edições, afirma que

Enquanto alguns apregoam que para salvar o país se
faz necessária a reeducação das elites, aparentemente
tão desviadas de seus deveres cívicos, de dirigir a vida
pública, eu sou daqueles que acreditam que a nossa
salvação está muito mais na educação adequada das
massas, no seio das quais se encontram enormes
reservas humanas até hoje deixadas à margem da ação
política e social pela falta de recursos educacionais
adequados e melhor distribuídos (CASTRO, 1984, p.
52).

Posição muito diferente daquela defendida, em 0 Livro Negro da Fome, publicado originalmente em 1957 e no qual ainda afirma que

cabe aos mentores da economia mundial encontrar uma salvação para a crise e não a atitude de querer 
transferir o seu encargo para os povos até hoje dominados pela força econômica das grandes potências. (...) Para alcançarmos esta nova era de paz e abundância, é necessário antes de tudo que os poucos homens que detêm em suas mãos o poder e com ele os destinos do mundo, nesta hora de transição, tenham maturidade política, sabedoria e boa vontade para iniciar um grande esforço de criação internacional para o qual são convidados pela força das circunstâncias (CASTRO, 1966, p. 45, grifo nosso)

Esta transformação no posicionamento político do autor não pode ser compreendida sem a consideração de sua atuação como Deputado Federal por Pernambuco (pelo Partido Trabalhista Brasileiro) e Diretor do Conselho Executivo da FAO (Organização das Nações Unidas para a Alimentação e Agricultura) nas décadas de 1950 e 1960. Schappo (2008) indica que esse foi um momento caracterizado pela aproximação entre Josué de Castro e os movimentos sociais do campo, em especial as Ligas Camponesas. Vale destacar que nas eleições de 1954 e 1958 Josué de Castro fez campanha para Deputado Federal ao lado de Francisco Julião, advogado e liderança das Ligas Camponesas que concorria para Deputado Estadual (SCHAPPO, 2008, p. 183).

Nesse período Josué de Castro organizou e participou do Seminário Latino-Americano sobre o Problema da Terra (1953), organizado pela FAO e com colaboração do governo brasileiro; do Primeiro Congresso de Camponeses Pernambucanos (1955), patrocinado pela FAO; e do Primeiro Congresso Nacional de Lavradores e Trabalhadores Agrícolas (1961). Além disso, como destaca Schappo (2008, p. 187)

$\mathrm{Na}$ década de 1960, Josué participa da criação do Movimento Nacional Pró-reforma Agrária, uma campanha desencadeada por pessedistas, petebistas e outros partidos pertencentes à Frente Parlamentar Nacionalista. 0 objetivo era esclarecer e instigar a opinião pública acerca do problema agrário brasileiro e a importância da reforma agrária para que o Congresso Nacional tenha cobertura popular, ao discutir e aprovar uma Lei de Reforma Agrária.

Por tudo isso é possível afirmar que a mudança no posicionamento político de Josué de Castro, quando ele deixa de apostar na conscientização das elites dirigentes e na cooperação com essas para transformar a realidade, não ocorreu de uma hora para outra, mas foi fruto de um processo. Se a crítica à monocultura e ao latifúndio, assim como a menção à reforma agrária, já estavam presentes em livros como Geografia da Fome e Geopolítica da Fome, o distanciamento em relação a uma posição política que privilegia o papel das elites dirigentes na solução de determinados problemas e uma aproximação de um posicionamento fundado nas aspirações políticas e no respaldo do povo pode ser entendido como uma novidade. Ou seja, seu pensamento e sua atuação política apresentam simultaneamente continuidades e descontinuidades.

À medida que o combate à fome não avançava e ele entrava em contato com um congresso avesso à transformações que questionassem o status quo, seu posicionamento político se alterava e se tornava mais crítico em relação às elites dirigentes e às perspectivas colocadas pela política desenvolvimentista que nacionalmente era impulsionada pelo Governo de Juscelino Kubitschek (1956 - 1961).

É o que podemos notar em suas declarações e ações como deputado federal por Pernambuco, sendo seu pronunciamento intitulado Sucessão presidencial, economia e reformas, realizado em 22 de maio de 1959 no Congresso Nacional sintomático. Nele o então deputado federal reconhece "a necessidade de promoção do desenvolvimento econômico para a emancipação do Brasil". No entanto, se contrapõe àqueles que "desejam o desenvolvimento econômico no seu stricto sensu, sem que ele venha a tocar, a alterar, no mais mínimo, a estrutura social vigente, na qual esses grupos ocupam uma posição de privilégios." Para ele, esse tipo de desenvolvimento que deveria ser caracterizado como colonialista, estava "totalmente desvinculado das aspirações políticas, sociais e culturais do povo" e "nada tem a ver com aquele que aspiramos e advogamos para o Brasil politicamente soberano" (CASTRO apud MELO; NEVES, 2007, p.135).

Por isso, demandava dos demais deputados a reorientação de suas condutas políticas, para que estas se aproximassem dos anseios populares, pois somente assim seria possível

manter a confiança do povo, dizendo com objetividade e honestidade o que se está passando no Brasil, pois não é dissimulando, nem escamoteando, que iremos defender nem o governo nem a nossa posição política. (...) Só assim poderemos contar com o povo para respaldar nossa ação; sem essa cooperação e respaldo do povo brasileiro, nenhum plano de desenvolvimento é válido, por falta de sentido social. (...) Embora não tenha o povo um conhecimento exato das causas que determinam a atual conjuntura nacional, ele tem uma consciência da realidade dessa conjuntura, através das repercussões sobre sua própria vida, de maneira que não mais se pode mistificar o povo, nem iludi-lo em suas convicções. (CASTRO apud MELO; NEVES, 2007, p.136, grifo nosso).

É importante destacar que na passagem acima Josué de Castro defende não apenas a legitimidade da participação popular, mas também a capacidade do povo de participar das decisões políticas do país. Deste modo, ele explicita sua crítica a uma democracia que sequer poderia ser qualificada como representativa, no 
sentido forte deste termo, uma vez que não conseguia identificar na atuação daqueles que haviam sido eleitos uma representação efetiva dos anseios da população. Também tornava clara sua contrariedade em relação aos planos de desenvolvimento que deixavam intactas "a estrutura social vigente", principalmente o latifúndio, caracterizado por "práticas agrícolas primitivas, de baixo rendimento e de alto grau de destruição da fertilidade dos solos" e responsável pela "existência das grandes massas dos sem-terra, dos que trabalham na terra alheia, como assalariados ou como servos explorados por esta engrenagem econômica de tipo feudal" (CASTRO apud MELO; NEVES, 2007, p.136 e 138).

Dois anos depois, em abril de 1961, em outro pronunciamento no Congresso Nacional ele insistia na importância da realização de reformas estruturais, uma vez

\begin{abstract}
que não é possível combater a fome apenas com paliativos para matar a fome de algumas crianças com um pouco de leite, senão com profundidade, com a reforma estrutural. Daí a necessidade de que esta Câmara venha a aprovar uma reforma agrária realmente consentânea com a nossa realidade, nem demagógica, nem inoperante, mas que atenda efetivamente à finalidade de arrebentar com o complexo do latifúndio, ao qual estão associadas a miséria, a improdutividade e a fome. (CASTRO apud MELO; NEVES, 2007, p.140, grifos nossos).
\end{abstract}

Em Sete Palmos de Terra e um Caixão, publicado pouco mais de três anos após esse pronunciamento, fica explícito que o autor não criava mais expectativas com relação ao papel das "elites dirigentes" ou dos "mentores da economia" no combate à fome. Esse posicionamento, tinha como fundamento sua interpretação do processo de colonização e como ele produziu uma distância intransponível entre uma "oligarquia restrita e poderosa" e a massa explorada economicamente e oprimida politicamente, impedindo assim a formação

\begin{abstract}
nesta área, pela sedimentação sociológica, a entidade povo, como expressão das aspirações e reivindicações de várias classes ou grupos sociais, e como força viva de orientação política do processo nacional. E foi esta ausência do povo, como entidade sociológica organicamente configurada, que explica a quase que ausência da revolução, no sentido clássico do termo, que deveria ter constituído o remate natural do episódio colonial (CASTRO, 1967, p. 139).
\end{abstract}

Isso nos ajuda a entender o porquê de sua atenção ter se voltado para a atuação das Ligas Camponesas. Afinal, por um lado elas eram entendidas por ele como produto da "tomada de consciência do povo (...) que tendo finalmente tomado consciência de sua existência como entidade política, procura dar expressão a seus anseios de reforma e de melhorias de suas desumanas condições de vida" (CASTRO, 1967, p. 147) ${ }^{5}$. Por outro, elas lutavam por uma reforma agrária que promovesse "maior justiça social, maior produtividade agrícola e maior participação das massas rurais no poder político" (CASTRO, 1967, p. 203, grifo nosso).

É nesse sentido que entendo que Josué de Castro reconhece as Ligas Camponesas como uma resposta política para a fome, afinal elas eram entendidas como o produto da tomada de consciência por parte dos camponeses de uma realidade social fundada na expropriação e na exploração, que os levava a reconhecer que a superação da fome não se daria sem a transformação do que ele chamava de estrutura social vigente. Tratava-se, de uma resposta que era produto da realidade social nordestina, da situação explosiva em que essa região se encontrava, e não de algo introduzido ou imposto de fora para dentro, como queria fazer crer o discurso anticomunista.

Assim o autor dava continuidade e potencializava seus trabalhos anteriores, pois é por meio da compreensão do sofrimento do homem do Nordeste, "submetido permanentemente ao flagelo da fome e esmagado pelo pavor constante da morte sempre presente na sua paisagem humana", que ele buscava entender "sua surda agitação política e a sua tensa explosividade" (CASTRO, 1967, p. 89). Em outras palavras, o entendimento mais profundo das Ligas Camponesas, que perturbavam os interesses dos latifundiários nordestinos, passava necessariamente pela compreensão da formação e consolidação de algo que Josué de Castro já havia analisado com profundidade: a "estrutura econômicosocial destas áreas, determinante, em última análise, deste estado de fome" (CASTRO, 1967, p. 42).

É nesse sentido, portanto, que Sete Palmos de Terra e um Caixão apresenta continuidades e descontinuidades em relação ao movimento de obra Josué de Castro. Para compreendermos como elas se articulam e ao mesmo tempo identificarmos a potência desse livro, é imprescindível que analisemos quais eram seus objetivos e sua perspectiva teórico-metodológica.
${ }^{5}$ Esse processo de conscientização estava diretamente relacionado, de acordo com Josué de Castro, com "o esforço de democratização da cultura que se iniciara na própria capital do Nordeste [Recife]" (CASTRO, 1967, p.150) e que teve no Movimento de Cultura Popular (MCP) sua força mais ativa. Para Souza (2014, p. 14) o MCP foi uma "experiência que ganhou notoriedade pelo esforço empreendido por seus militantes no sentido de acelerar a elevação do nível material e o desenvolvimento cultural do povo pernambucano, em uma sociedade em que a maioria da população, por ser analfabeta, não tinha uma participação ativa na vida política institucionalizada do país, por ser proibida de votar. Educar, essa foi a palavra de ordem do MCP. Educar pelo rádio, pelo cinema, pela televisão, pela imprensa, pelas artes plásticas, pelo teatro, pela música, por meio de métodos informais de educação em praças públicas". 
A desmistificação das Ligas Camponesas e a defesa da Reforma Agrária

Já na introdução Josué de Castro deixa claro que seu principal objetivo ao escrever Sete Palmos de Terra e um Caixão era "obter aliados conscientes para defender certas ideias que (...) merecem ser ardorosamente defendidas" (CASTRO, 1967, p. 13). Para isso, ele reconhecia ser imprescindível opor-se às falsas representações tanto da situação política, econômica e social do Nordeste, como da atuação das Ligas Camponesas.

Como indicado acima, num contexto de preocupação crescente com a propagação do comunismo, a imprensa norte americana demonstrava grande interesse pelo Nordeste brasileiro. Entre os muitos textos jornalísticos que foram publicados nos Estados Unidos naquele período, Josué de Castro toma como "documento modelo" a reportagem escrita por Tad Szulc e publicada no fim do ano de 1960 no New York Times ${ }^{6}$.

Imigrante polonês, que havia vivido no Brasil entre 1940 e 1947, Szulc (1960a) alertava para uma situação em que "os ingredientes de uma situação revolucionária" se tornavam cada vez mais aparentes e na qual "agitadores de esquerda" exploravam a miséria e as secas periódicas para doutrinar a população nordestina. De acordo com esse jornalista,

[os] homens das Ligas dizem aos camponeses que a miséria não é necessária. Eles os impulsionam a defenderem seus interesses locais, que invariavelmente necessitam ser defendidos. Vem então a doutrinação política e a conversa sobre revolução (SZULC, 1960a).

Como forma de alertar para o perigo de uma nova revolução em território latino-americano, Szulc (1960a) chamava atenção para o fato de haver um "amplo acordo entre autoridades locais, políticos e sociólogos", que entendiam que em alguns anos seria "inevitável um surto revolucionário de grande dimensão", a não ser que algo fosse "feito rapidamente pelo Nordeste em termos de uma mudança básica em sua estrutura econômica e social".

Como o próprio Josué de Castro (1967, p.144) reconhece, "o título da segunda parte do artigo 'Os marxistas estão organizando os camponeses no Brasil', exprime bem a preocupação com a influência comunista", que estava diretamente relacionada com a Revolução Cubana, uma vez que Szulc (1960b) afirmava que "fora de Cuba, a Liga parece ser a coisa mais próxima de um movimento 'fidelista' organizado na América Latina".

Essa associação entre as Ligas Camponesas e a Revolução Cubana também está presente em editorial publicado no mesmo dia pelo New York Times. Intitulado "Os fidelistas do Brasil", o texto sintetiza alguns dos principais pontos das reportagens de Szulc, mas também expressa o posicionamento desse jornal em relação à necessidade de uma resposta da política externa americana frente à mobilização social que ganhava força no Nordeste. Primeiramente, afirmam que "os 'fidelistas' e os comunistas não trariam qualquer alívio [para os pobres trabalhadores e fazendeiros], pois a mera confiscação de terras provavelmente não aumentaria sua produtividade e porque promessas não enchem a barriga" para na sequência concluir que

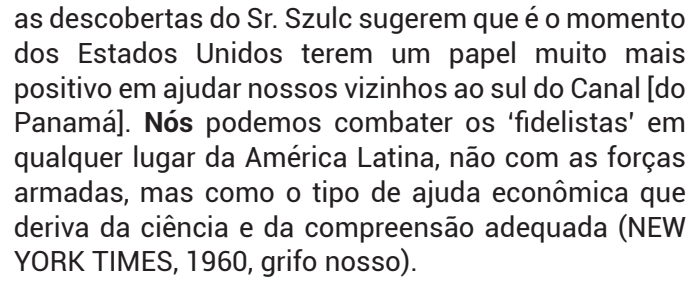

Cabe perguntar quem exatamente constitui o "nós" na citação acima, mas fica evidente a tentativa do editorial de falar pela sociedade americana como um todo e mesmo pelo Estado. De toda forma, o uso do "nós" revela a sintonia entre as posições do jornal e do Departamento de Estado ${ }^{7}$ dos Estados Unidos em relação aos "fidelistas" e comunistas e no tocante a qual seria a melhor estratégia de combatê-los. Essa sintonia ficou ainda mais evidente em agosto de 1961, quando foi lançado o programa Aliança para o Progresso, apresentado como um programa de assistência ao desenvolvimento econômico que tinha como objetivo ajudar os vizinhos latino-americanos a evitar surtos revolucionários.

A Aliança para o Progresso deve ser entendida como "o braço político visível da teoria da modernização na América Latina" (SILVA, 2018, p. 95). Esta teoria, que gozava de bastante prestígio nos Estados 
Unidos ${ }^{8}$, representava os anseios do liberalismo e se apresentava como uma "alternativa tecnocrática ao socialismo" (SILVA, 2018, p. 92), chegando, inclusive, ao ponto de delinear uma escala civilizatória que tinha como ápice a cultura anglo-saxã e os ideais norteamericanos. Era nesse contexto e com esse sentido que o desenvolvimento fora pensado como uma das armas da política externa norte-americana.

Como se sabe, a Aliança para o Progresso nunca chegou perto de resolver o problema do subdesenvolvimento na América Latina, mas isso não significa que ela não tenha atingido seus objetivos. Afınal, como explicita Francisco de Oliveira (1981, p. 121), as recomendações de uma missão da Aliança para o Progresso que visitou o Nordeste no fim de 1961 consistiam em um "programa-impacto, de caráter estritamente assistencialista, cujo objetivo expresso era o de esvaziar politicamente o movimento das Ligas Camponesas, solapar a liderança das forças populares emergentes no Nordeste".

Para Josué de Castro era imprescindível indicar como os principais meios de comunicação distorciam a realidade e alimentavam o medo, abrindo caminho para todo tipo de ação que evitasse a mobilização social. Ele não nega que o texto de Szulc trazia dados sobre a realidade social do Nordeste e tampouco desconsidera que ele denunciava o pauperismo generalizado que caracterizava essa região; contudo, se contrapõe à representação que esse jornalista cria das Ligas Camponesas e da "situação explosiva" que caracterizava o Nordeste.

Sua análise da situação socioeconômica é justa, mas sua interpretação se afasta do real, quando ele liga este fenômeno social mais às influências ideológicas vindas de fora do que à marcha do próprio processo cultural brasileiro. Erra o jornalista em supor que a explosividade do Nordeste se alimentou, principalmente dos mitos de Mao Tsé-tung e Fidel Castro e dos exemplo da Revolução Chinesa e da Cubana. Aí é que não lhe ajudou a decifrar o enigma do Nordeste a falta de um conhecimento mais profundo da história da região, dos seus antecedentes remotos e da transformação mais recente processada na consciência do povo brasileiro a partir do começo deste século (CASTRO, 1967, p.146)

Três críticas se sobressaem nessa passagem. Em primeiro lugar, a discordância com relação à leitura

\footnotetext{
${ }^{8 " A}$ teoria da modernização foi pensada por vários cientistas sociais a partir do entreguerras até encontrar seu apogeu na administração Kennedy e seu ocaso no desastre vietnamita durante o governo Johnson. Os três principais loci institucionais em que esta teoria foi pensada durante este período foram o Departament of Social Relations (DSR), de Harvard, o Committee of Comparative Politics (CCP), ligado ao Social Science Research Council (SSRC), que apesar de constituir um painel independente, estava largamente amparado por scholars de Princeton e Yale, e o Center for International Studies, do MIT [Massachusetts Institute of Technology]. Ou seja, é basicamente uma invenção das prestigiadas Ivy League americanas." (SILVA, 2018, p. 94)
}

que via as Ligas Camponesas como mero produto da doutrinação de agitadores esquerdistas. Em segundo lugar, sem ignorar a inspiração proporcionada pela Revolução Cubana e a relação que socialistas e comunistas tinham com as Ligas Camponesas, Josué de Castro divergia com relação ao papel das influências externas na formação e consolidação das Ligas. Por fim, não reconhecia naquele momento a iminência de um processo revolucionário.

Para ele era importante se contrapor a essa representação do que ocorria no Nordeste e explicitar "como pode um fenômeno social ser totalmente distorcido em sua realidade pelas falsas interpretações do jornalismo tendencioso ou sensacionalista" (CASTRO, 1967, p.34). Do seu ponto de vista, a compreensão das Ligas Camponesas passava necessariamente pelo resgate de suas origens, assim como pela compreensão aprofundada do espaço e da sociedade em que esse movimento social havia se formado. Só assim seria possível compreender

como uma iniciativa brotada das tradições do feudalismo agrário, aí reinante, com objetivos humanitários e pacíficos, [pôde] se transformar num instrumento revolucionário, de explosiva agitação social, em face da cega incompreensão e da obstinada resistência da própria estrutura feudal (CASTRO, 1967, p.35).

É por essa razão que Josué de Castro dedica o primeiro capítulo do livro a explicar o que ele denomina como "a reivindicação dos mortos". De acordo com ele, a fundação da primeira das Ligas Camponesas no Nordeste brasileiro em 1955 por João Firmino tinha como objetivo

\footnotetext{
defender os interesses e os direitos dos mortos, não os dos vivos. Os interesses dos mortos de fome e de misérias; os direitos dos camponeses mortos na extrema miséria da bagaceira. E para lhes dar o direito de dispor de sete palmos de terra onde descansar os seus ossos e o de fazer descer o seu corpo à sepultura dentro de um caixão de madeira de propriedade do morto, para com ele apodrecer lentamente pela eternidade afora (CASTRO, 1967, p.23, grifo nosso).
}

Essa situação aparentemente paradoxal, a luta pelos direitos dos mortos e não por uma vida melhor, não apenas dá nome ao livro, como também é seu ponto de partida para explicar a situação do Nordeste e a força das Ligas Camponesas. Para ele, a "desvairada aspiração de possuir, depois de morto, sete palmos de terra por parte de quem na vida não dispusera, de seu, nem de uma polegada de solo" e "o desespero em possuir um caixão próprio para ser enterrado, quando em vida esses deserdados da sorte nunca foram proprietários de nada" 
só faz sentido quando se

compreende que, para os camponeses do Nordeste, a morte é que conta, não a vida, desde que, praticamente, a vida não thes pertence (...) Daí o interesse do camponês do Nordeste pelo cerimonial da morte, que ele encara como o da sua libertação à opressão e ao sofrimento da vida (CASTRO, 1967, p. 24).

Tendo convivido desde a infância com o povo nordestino eestudado profundamenteo a formação dessa região, o autor reconhecia muitos traços característicos da visão de mundo que esses camponeses carregavam. Ele sabia, entre outras coisas, que para esses homens e mulheres era imprescindível

\begin{abstract}
se apresentarem diante de Deus com as mãos limpas de crimes e com a alma limpa de vícios. $E$ isto não seria difícil para a maioria deles. Mas no seu entender simplista, seria também necessário se apresentarem com um mínimo de decência, numa hora de tamanha importância e de tanta solenidade: a hora do juízo final. E é aí que a sua extrema miséria não lhes permitia este mínimo de decência (CASTRO, 1967, p. 28).
\end{abstract}

Deste modo, era inaceitável para essas pessoas serem sepultadas com um "caixão de caridade", emprestado pela Prefeitura, mas que era

restituído na boca da cova, para servir outros defuntos (...) Ora, ser enterrado desta forma, constitui a humilhação suprema para essa pobre gente, cuja vida não passa de um rosário de humilhações. Mas esta é a maior de todas, porque é uma humilhação que passará para o outro lado da vida - uma humilhação que durará toda a eternidade. A Liga foi criada para evitar esta suprema humilhação (CASTRO, 1967, p. 28).

A primeira das Ligas Camponesas no Nordeste nasce, portanto, como uma sociedade civil beneficente ou de auxílio-mútuo, com o objetivo de providenciar um sepultamento digno àqueles que não tinham sequer os recursos necessários para comprar um caixão. No entanto, essa iniciativa que reivindicava o direito dos mortos foi rapidamente reprimida pelos grandes proprietários de terra do Nordeste, que viram essa experiência como um perigoso instrumento de agitação social. E foi exatamente a tentativa de reprimir essa mobilização que despertou a resistência dos camponeses, que a partir daquele momento passam, segundo Josué de Castro, a reivindicar o direito dos vivos.

Josué de Castro identificou uma relação complexa entre as Ligas Camponesas e o Partido Comunista. Para ele, as Ligas Camponesas no Nordeste foram criadas "dentro do espírito do cristianismo primitivo, que até hoje impregna a alma coletiva da população nordestina" e que por conta disso "foram mesmo, em certa fase, mal vistas e tenazmente combatidas pelos líderes marxistas da região" (CASTRO, 1967, p. 35). Isso não significa que ele desconsiderasse a aliança que, de fato, existiu entre as Ligas Camponesas e diferentes grupos de esquerda, entre eles o Partido Comunista. No entanto, ele problematizava essa relação ao afirmar que ela tinha como fundamento a "luta comum pela emancipação da massa camponesa" e a "experiência vivida e sofrida por essa massa humana" (CASTRO, 1967, p. 35).

Ao mesmo tempo, ele também nega que as Ligas Camponesas eram o produto da ação de lideranças, ou como aparecia no noticiário, o produto da ação de "instigadores da revolução social do Nordeste" (CASTRO, 1967, p. 193). É certo que figuras importantes como Miguel Arraes, Francisco Julião, os padres da Reforma Agrária e Celso Furtado personificavam de alguma maneira "o impulso natural do movimento de emancipação de um povo" (CASTRO, 1967, p. 193). Porém, para ele, o sujeito político das transformações que se processavam no Nordeste era o povo ou a massa de camponeses. Assim, concluía que seria

$$
\begin{aligned}
& \text { ingênuo pensar que foi Julião quem inventou o } \\
& \text { problema agrário no Nordeste, que foi Arraes o autor } \\
& \text { da escravidão branca e das aspirações de justiça } \\
& \text { social, que foi Celso Furtado o revelador da economia } \\
& \text { dependente ou que fui eu quem inventou a fome. Não } \\
& \text { inventamos nada (CASTRO, 1967, p. 193). }
\end{aligned}
$$

Por fim, é importante destacar que ele discordava daqueles que entendiam que as Ligas Camponesas possuíam "uma estruturação funcional e uma liderança suficientemente vigorosa para desencadearem um verdadeiro processo revolucionário". (CASTRO, 1967, p. 36). As Ligas estavam longe disso e, se haviam assustado os latifundiários e seus associados, era por conta do "pavor que os leva a ver no menor gesto ou atitude de inconformismo das massas espoliadas, um perigo tremendo para a manutenção dos seus privilégios" (CASTRO, 1967, p. 36).

Em síntese, Josué de Castro indicava que a representação produzida pela imprensa da explosão que marcavam o Nordeste nos anos 1950 e 1960 seria mistificadora e ocultaria suas verdadeiras causas: o descontentamento social causado pela extrema miséria.

Ao construir uma argumentação cujo fundamento é a compreensão desse descontentamento social, Josué de Castro trouxe contribuições ainda hoje essenciais para o debate sobre o combate à fome. Em primeiro lugar, em Sete Palmos de Terra e um Caixão há um claro posicionamento em relação à impossibilidade de superação da fome e da miséria por meio de políticas conciliatórias que não enfrentassem abertamente os grandes proprietários de terra (o latifúndio). Se a fome 
é produto de relações sociais fundadas na exploração e expropriação dos trabalhadores não há como pensar sua superação sem questionar a ordem social vigente. Ao mesmo tempo, o autor revela ser imprescindível considerar a divisão internacional do trabalho, uma vez que o lugar ocupado pelo Brasil (ou pela América Latina) como exportador de produtos primários na divisão internacional do trabalho constitui um processo espoliativo do qual as elites dirigentes são cúmplices e que é responsável pelo irrisório poder de compra dos trabalhadores (CASTRO, 1967, p. 181). Por fim, ele contesta aqueles que defendiam a democracia como um princípio abstrato ao defender que esta só era verdadeira quando "os benefícios da liberdade e da riqueza que são hoje reservados exclusivamente a uma classe dominante" fossem estendidos ao povo (CASTRO, 1967, p. 211).

Como colocado acima, todo esse esforço tinha como sentido último obter aliados na luta pela reforma agrária, entendia por Josué de Castro naquele momento como o principal mecanismo de combate à fome. Mais adiante retomarei como esse objetivo se relaciona com a perspectiva teórico-metodológica do autor e está em consonância com o que ele entende ser o papel dos intelectuais ou do pesquisadores militantes. Antes disso, gostaria de explorar o sentido político desse objetivo.

Josué de Castro não é ingênuo em relação ao que a ciência pode fazer e não acredita "que qualquer interpretação de sua realidade, por mais lúcida que ela seja, possa ter a virtude mágica de mudar a direção da História e de resolver da noite para o dia os angustiantes problemas da região" (CASTRO, 1967, p. 19). Ele reconhece que a conscientização, por mais importante que seja, não oferece nenhuma garantia de transformação da realidade; também sabe que tomar a conscientização e a mobilização de seus leitores como objetivos não é uma tarefa que possa ser executada individualmente ou em apenas um livro, ainda mais em um país que iniciava a década de $1960 \mathrm{com}$ uma taxa de analfabetismo de aproximadamente $40 \%$ de acordo com o Censo Demográfico do Instituto Brasileiro de Geografia e Estatística (IBGE).

Deste modo, o objetivo de "obter aliados conscientes" precisa ser entendido, sobretudo, como uma perspectiva que guia o trabalho do autor e que impacta claramente na forma como ele apresenta suas reflexões. $O$ fato de seus leitores ou interlocutores não serem necessariamente outros pesquisadores lhe impõe o desafio de escrever um livro que seja ao mesmo tempo profundo e acessível. Além disso, ele tampouco escreve apenas para aqueles que já defendem a realização da reforma agrária, o que implica a necessidade de construir uma argumentação extensa e cuidadosa sobre sua necessidade.

Ao escrever um livro a pedido de uma editora norte americana para o público desse país, o autor buscava conquistar aliados externos na defesa da democracia e da reforma agrária. No entanto, ele sabia que para construir essa ponte seria necessário superar falsas representações de ambos os lados. Desse modo, declarava que

nem o Nordeste é apenas um bando de agitadores e
de comunistas, nem os EUA são apenas um bando
de sanguessugas chupando impiedosamente todo o
sangue - todo o trabalho e toda a riqueza - dos latino-
americanos. Vamos tentar pôr as coisas nos seus
devidos termos (CASTRO, 1967, p. 166).

Em outras palavras, Josué de Castro entendia que uma possível aliança entre o público norte-americano e os nordestinos dependia da conscientização de ambos os lados. Ele reconhecia a existência de um forte sentimento antiamericano entre aqueles que haviam compreendido como a política econômica executada pelos grupos econômicos norte-americanos com o apoio do Departamento de Estado havia conduzido a América Latina a uma situação trágica (CASTRO, 1967, p. 166). Entretanto, sem negar a legitimidade dessa crítica, ele indicava que era imprescindível superar a confusão provocada pela indistinção entre "todo o povo norteamericano [e] estes grupos financeiros" (CASTRO, 1967, p. 166).

São muitas as passagens na qual ele explicita seu entendimento de que "a análise acurada dos fatores subterrâneos desse drama sociológico e a sua revelação à consciência coletiva ajudarão o processo de conscientização das massas nordestinas" (CASTRO, 1967, p. 19). Por conseguinte, é possível afirmar que mesmo tendo sido escrito a pedido de uma editora norteamericana o livro também tinha como interlocutores os próprios nordestinos.

Em suma, ao propor uma compreensão mais rigorosa da realidade e comprometida com a transformação desta, Josué de Castro revelava seu desejo de contribuir com a formação de alianças internacionais, baseadas na solidariedade entre diferentes povos que sofriam com processos semelhantes de expropriação e exploração, e posicionava-se criticamente frente às rivalidades nacionalistas.

A perspectiva teórico-metodológica de Josué de Castro em Sete Palmos de Terra e um Caixão

Como indicado acima, o posicionamento político de Josué de Castro neste livro é diferente daquele adotado 
em obras anteriores. Teórica e metodologicamente essa mudança foi acompanhada pela crítica à neutralidade científica, que para Josué de Castro atua como uma camisa de força que faz do pesquisador "um simples inventariante de tudo aquilo que se apresenta aos seus olhos, teleguiados por métodos de trabalho consagrados" (CASTRO, 1967, p. 14). Assim, ele se contrapunha à

\begin{abstract}
antiga sociologia, que se presumia científica, mas não passava em seu falso cientificismo de um instrumento de inconsciente mistificação da realidade social, cujo contato direto ela sempre evitava, preocupada pela fragilidade dos sistemas em vigor e pelo receio de que ao menor contado tudo pudesse vir abaixo. No fundo, a antiga sociologia era mais utópica do que científica, e a sua utopia consistia exatamente no seu inconsciente desejo de que o processo social se imobilizasse, para ser melhor fotografado (CASTRO, 1967, p. 15).
\end{abstract}

Assim, explicitava o sentido político do método e ao mesmo tempo contestava as metodologias de pesquisa que estavam conscientemente ou não comprometidas com a manutenção da estrutura social existente ou, nas suas palavras, com a imobilização do processo social. Em outras palavras, ele não apenas reconhecia que sua perspectiva teórico-metodológica estava atravessada pela defesa das mudanças sociais, como buscava revelar de que modo aqueles que se apresentavam como neutros (ou científicos) também se posicionavam politicamente frente à realidade.

É nesse mesmo sentido que ele recusa o lugar-comum que define a pesquisa comprometida ou engajada como menos científica. Pelo contrário, para ele

uma sociologia que estudando cientificamente a formação, a organização e a transformação de uma sociedade em vias de desenvolvimento, compreende e admite que os valores mais desejáveis por esta sociedade são os ligados à mudança e não à estabilidade, e, por isto mesmo, se aplica em aprofundar ao máximo o seu conhecimento científico do mecanismo destas mudanças (CASTRO, 1967, p. 15).

Subjaz o entendimento de que a ciência deve servir à compreensão de uma realidade sempre em movimento, em processo de transformação constante e para isso ela não pode recorrer a métodos que imobilizam a realidade. Além disso, ao afirmar que os "valores mais desejáveis" estavam associados à mudança, reforçava o sentido político de uma perspectiva teórico-metodológica que "não tem o menor interesse em encobrir os traços de uma realidade social, cuja revelação possa acarretar prejuízos a determinados grupos ou classes dominantes" (CASTRO, 1967, p. 15).

Outro aspecto teórico-metodológico que merece atenção é o fato de Josué de Castro entender como algo positivo o fato de ele ser alguém "impregnado de corpo e alma da vida desta terra e do sentimento de sua gente" (CASTRO, 1967, p. 16) em oposição ao que ele entende como uma idealização dos pesquisadores que partem de "imagens preconcebidas do seu conhecimento existencial" (CASTRO, 1967, p. 16) e acabam por produzir interpretações etnocêntricas da realidade.

Por conta disso ele não tem receio em afirmar que seu objetivo era produzir "um retrato do Nordeste como o vê um homem desta região"; retrato com deformações menores do que aqueles produzidos por autores que, presos"àsrealidadessociaiscomqueestãofamiliarizados em seus países" procuravam compreender essa região "através do método comparativo" (CASTRO, 1967, p. 16). Isso não significa que Josué de Castro entenda que ele está imune ao risco de produzir uma imagem distorcida da realidade, uma vez que para ele a "inserção inevitável do observador sociológico dentro do processo social (...) torna impossível a sua não participação nos fenômenos que ele observa, invalidando a sua pretensão de obter uma imagem do real que não seja deformada" (CASTRO, 1967, p. 16). No entanto, é preciso se contrapor àquilo que aparece como universal, como um modelo para todo o mundo, pois "até então era como se só o Ocidente existisse (e o Ocidente era apenas o conjunto dos países colocados dos dois lados do Atlântico Norte), e como se o resto do mundo fosse apenas uma vaga massa de terra sem maior interesse nem significação" (CASTRO, 1967, p. 20).

Nesse aspecto é possível afirmar que o autor se aproximava naquele momento dos debates e lutas anticoloniais que ganhavam força desde os anos 1950 . Nesse livro sua leitura crítica do processo de colonização brasileiro passa a ser acompanhada também pelo questionamento do "pensamento ocidental" e das teorias e métodos por ele consagrados.

Por fim, é importante reconhecer também sua busca por superar as fronteiras convencionais do conhecimento científico e à especialização que perde de vista a totalidade. Para ele nenhuma ciência ou pesquisador seriam capazes de isoladamente compreender em sua totalidade todas as nuances de uma sociedade. Não há um setor de especialistas "sejam eles geógrafos ou antropólogos, sociólogos ou economistas" (CASTRO, 1967, p. 18) que possa explicar toda a realidade.

Em Sete Palmos de Terra e um Caixão a defesa da interdisciplinaridade se apresenta como um elemento central de sua crítica ao pensamento economicista e tecnicista. Em claro diálogo com o contexto em que vivia, Josué de Castro afirma que o processo de desenvolvimento

realmente extrapola os limites de qualquer disciplina e 
este tem sido um dos principais motivos dos seguidos fracassos dos planos de desenvolvimento elaborados no papel, por economistas renomados, que dispunham, entretanto, apenas de uma visão puramente econômica do problema (CASTRO,1967, p. 18).

Ao mesmo tempo, ele faz questão de ressaltar que os problemas que o Nordeste enfrentava não seriam superados por meio de soluções hidráulicas para o problema das secas. Assim, Josué de Castro assumia um posicionamento crítico em relação aos organismos que desde o fim do século XIX eram criados com "a missão específica de estabelecer e superintender um plano sistemático de combate às secas" (CASTRO, 1967, p. 185), assim como em relação a própria SUDENE (Superintendência do Desenvolvimento do Nordeste, criada em 1959), que de início teria sido influenciada pelo "exagerado tecnicismo de seus colaboradores" (CASTRO, 1967, p. 207) e não havia concedido nenhuma atenção aos problemas relativos à estrutura agrária.

Assim sendo, é possível afirmar que neste livro as contribuições do autor não estão restritas à explicação da situação explosiva em que o Nordeste se encontrava e à defesa da reforma agrária, uma vez que ele também apresenta um rico debate teórico-metodológico no qual a crítica à neutralidade científica e ao pensamento economicista e tecnicista tem centralidade.

\section{Considerações finais}

A vida de Josué de Castro foi marcada por seu compromisso com a transformação da realidade, por seu desejo de interpretar as relações sociais e ao mesmo tempo participar de sua transformação. Se neste artigo procuro destacar algumas das descontinuidades que Sete Palmos de Terra e um Caixão apresenta em relação ao movimento da obra de Josué de Castro é porque elas apontam para correções de rumo (tanto em sua atuação política quanto em sua longa trajetória acadêmica) que o próprio autor entendeu como necessárias. Se por um lado podemos ler essas mudanças ou correções como reveladoras dos limites que o próprio Josué de Castro passou a identificar em sua atuação; por outro, é possível refletir sobre a pertinência e atualidade de sua posição tanto com relação às elites dirigentes e aos movimentos sociais, quanto no que se refere à necessidade de uma clara ruptura com a ordem social vigente para a superação da fome.

0 início de século XXI no Brasil foi marcado pelo esforço em combater a miséria e a fome no país. Como consequência de um conjunto de políticas do governo federal, entre elas o Programa Fome Zero (criado em
2003 e rebatizado como Programa Brasil Sem Miséria em 2011) e a política de o aumento real do salário mínimo, a proporção de domicílios em situação de insegurança alimentar que em 2004 era de aproximadamente 35\% passou para 22,6\% em 2013 (IBGE, 2014).

Apesar dos avanços incontestáveis em termos de redução da miséria, este esforço incomum em nossa história não foi capaz de erradicar a fome e em muitos aspectos esteve aquém da perspectiva vislumbrada por Josué de Castro. Durante os anos em que o PT esteve à frente da presidência houve uma clara tentativa de combater a fome sem um nítido enfrentamento da ordem social vigente, especialmente no que se refere ao latifúndio, que hoje se apresenta como agronegócio. Tampouco nos deslocamos na divisão internacional do trabalho. Pelo contrário, foram as exportações de produtos primários que em grande medida geraram os recursos utilizados no combate à miséria. Por fım, não vivemos um processo no qual os trabalhadores foram entendidos como agentes políticos capazes de decidir (não apenas) como serão produzidos, distribuídos e consumidos os alimentos.

Lamentavelmente mesmo essa experiência moderada de combate à miséria e à fome foi abortada por uma nova forma de golpe que se difunde na América Latina. Assim como em 1964, não foi necessária a ameaça de uma revolução para que uma espécie de obsessão anticomunista orientasse uma ascensão conservadora que interessa principalmente aos grandes proprietários (de terra e capital).

$\mathrm{Na}$ ausência de dados atualizados sobre a insegurança alimentar e a fome no país ${ }^{9}$, diversos indicadores socioeconômicos apontam para uma deterioração nas condições de vida de uma parcela expressiva da população. De acordo com o IBGE (2019), desde 2015 houve um aumento na taxa composta da subutilização da força de trabalho ${ }^{10}$, redução do pessoal ocupado com vínculo formal, queda no rendimento médio do trabalho e do rendimento médio domiciliar per capita, o que nos ajuda a entender o aumento da pobreza e da extrema pobreza no país. "Em 2018, no Brasil, havia $25,3 \%$ da população com rendimentos inferiores a US\$ $5,50 \mathrm{PPC}^{11}$ por dia, aproximadamente $\mathrm{R} \$ 420$ mensais, o

${ }^{9} \mathrm{~A}$ publicação desses dados pelo IBGE estava prevista para 2019. Até o momento da redação desse artigo (janeiro de 2020) esses dados ainda não haviam sido publicados.

10"Proporção da população subocupada por insuficiência de horas somada à população desocupada e à força de trabalho potencial, tendo como denominador a força de trabalho ampliada." (IBGE, 2019, p. 127)

11"A PPC [Paridade de Poder de Compra] é utilizada para comparar o poder de compra entre diferentes países, ou moedas, e é utilizada como alternativa à taxa de câmbio, que, em geral varia com mudanças nos índices de preços e mesmo a volatilidade do mercado de capitais e especulação. O fator de conversão de PPC é o número de unidades da moeda de um país necessárias para comprar a mesma quantidade de bens e serviços no mercado interno como dólares comprariam nos Estados Unidos." (IBGE, 2019, p. 57) 
que equivale a cerca de $44 \%$ do salário mínimo vigente em 2018" (IBGE, 2019, p. 58). Dos 52,5 milhões de brasileiros que se encontravam nessa situação, 13,5 milhões (ou $6,5 \%$ da população total) tinham renda mensal per capita inferior a R\$ 145 .

Entendo que neste momento é preciso recolocar a fome no centro do debate sobre os problemas sociais brasileiros e apontar para a necessidade de transformações estruturais em nossa sociedade. É possível reconhecer, como indicado acima, que muitos dos obstáculos identificados por Josué de Castro no início dos anos 1960 permanecem sendo os obstáculos encontrados na América Latina, e mais especificamente no Brasil, nesse início do século XXI. A fome e a miséria persistem, assim como as ilusórias respostas tecnicistas e economicistas para os problemas sociais; a visão de mundo das classes dominantes segue sendo representada como neutra e universal enquanto os movimentos sociais continuam sofrendo com os efeitos de representações mistificadoras que buscam deslegitimá-los e criminalizá-los.

Para além da análise das Ligas Camponesas e do comprometimento de Josué de Castro com a luta que elas empreendiam, nos interessa especificamente aqui o fato de ele ter se afastado a partir de meados dos anos 1950 de uma perspectiva de transformação da realidade fundada na atuação junto às elites dirigentes em direção a uma perspectiva que toma os movimentos sociais como agentes políticos privilegiados para transformar os fundamentos de nossas sociedades.

A meu ver essa descontinuidade produziu uma das mais importantes contribuições de Josué de Castro para enfrentarmos os problemas relativos à alimentação. Ao ímpeto de técnicos, pesquisadores, políticos, empresários e intelectuais em oferecer soluções ou respostas prontas para os problemas enfrentados pela população, Josué de Castro contrapõe uma noção que coloca os trabalhadores (mesmo os mais empobrecidos) como sujeitos que têm condições de se organizar para transformarem suas próprias condições de vida. Isto é, em Sete Palmos de Terra e um Caixão aqueles que vivem miseravelmente e que passam fome não aparecem como pessoas que precisam ser socorridas ou tuteladas, mas como agentes políticos que ao se organizarem e tomarem consciência dos processos de expropriação e exploração aos quais estão submetidos têm condições de pensar os caminhos de sua emancipação.

Como indicado acima, Josué de Castro não desconsiderava a percepção que os nordestinos tinham da realidade em que viviam e via nessa percepção o ponto de partida de seu processo de conscientização. Para ele, foi no momento em que perceberam que sua extrema miséria não lhes permitia que se apresentassem com o mínimo de decência na "hora do juízo final" que esses camponeses tomaram "consciência da sua realidade social". E, por terem "tomado consciência de sua existência como entidade política, procura[m] dar expressão a seus anseios de reforma e de melhorias de suas desumanas condições de vida" (CASTRO, 1967, p. 147).

Ao mesmo tempo, Josué de Castro apostava na parceria entre movimentos sociais, intelectuais $\mathrm{e}$ militantes comprometidos com a transformação da realidade, uma vez que para ele era necessária a produção de um conhecimento aprofundado da realidade para que as "forças ou tensões sociais [fossem] convenientemente dirigidas num sentido construtivo e criador" (CASTRO, 1967, p. 18). Assim, sem subestimá-las ou tentar substituí-las, tanto intelectuais como militantes poderiam contribuir com o "processo de conscientização das massas nordestinas" (CASTRO, 1967, p. 19) e, ao mesmo tempo, ganhariam consciência da realidade em contato com elas.

No fundo, para Josué de Castro, era essa conscientização que havia criado uma situação explosiva. Essa perspectiva, que se opõe àquela que tem como objetivo desconsiderar ou combater violentamente os movimentos sociais e vê na organização política dos trabalhadores o resultado da exploração ou doutrinação de agitadores, faz com que para ele a reforma agrária não consista apenas na distribuição de terras e equipamentos para os camponeses, mas também, e sobretudo, na maior participação deles no poder político.

Neste mesmo sentido, é possível afirmar que a luta pela superação da fome nos dias de hoje não pode estar restrita às demandas por alimento, renda, ou mesmo pela distribuição de terra. Ela deve incluir necessariamente a luta pela participação nas decisões políticas e econômicas que determinam as condições de vida em uma determinada sociedade. Ou, para ser mais específico, a superação da fome passa necessariamente pela participação popular nas decisões de como a sociedade vai produzir, distribuir e consumir os alimentos necessários à sua reprodução. Por fim, é preciso reconhecer que o combate à miséria e à fome passam pela compreensão das relações sociais de produção e pelo enfrentamento das formas de exploração e expropriação que caracterizam nossa sociedade. Josué de Castro é uma referência importante nessa caminhada. 


\section{Referências}

ABREU, Alzira Alves de et al (coords.). Dicionário Histórico-Biográfico Brasileiro - Pós-1930. Rio de Janeiro: CPDOC, 2010. Disponível em: <http://cpdoc.fgv.br.>. Acesso em: 26 ago. 2019.

BOTELHO, André. Passado e futuro das interpretações do país. Tempo Social, v. 22, n. 1, p. 47-66, 1 jun. 2010.

CANDIDO, Antonio. A sociologia no Brasil. Tempo Social, v. 18, n. 1, p. 271-301, 1 jun. 2006.

CASTRO, Josué de. A Alimentação Brasileira à Luz da Geografia Humana. Porto Alegre: Globo, 1937.

Geografia da Fome: o dilema brasileiro: pão ou aço. Rio de Janeiro: O Cruzeiro, 1948.

Geopolítica da Fome. São Paulo: Brasiliense, 1965.

O Livro Negro da Fome. São Paulo: Brasiliense, 1966.

Sete Palmos de Terra e um Caixão. São Paulo: Brasiliense, 1967.

Geografia da Fome: o dilema brasileiro: pão ou aço. Rio de Janeiro: Edições Antares, 1984.

Homens e Caranguejos. São Paulo: Brasiliense, 2001.

INSTITUTO BRASILEIRO DE GEOGRAFIA E ESTATÍSTICA (IBGE). Pesquisa Nacional por Amostra de Domicílios:

Segurança Alimentar - 2013. Rio de Janeiro: IBGE, 2014.

Síntese dos Indicadores Sociais - Uma análise das condições de vida da população brasileira - 2019. Rio de Janeiro: IBGE, 2019.

MELO, Marcelo Mário e NEVES, Tereza Cristina Wanderley. (orgs.) Josué de Castro. Brasília: Câmara dos Deputados, Coordenação de Publicações, Série Perfis Parlamentares, no.52, 2007.

NEW YORK TIMES. The 'Fidelistas' of Brazil. New York Times, Nova York, 1 nov. 1960. Disponível em: https://www. nytimes.com/1960/11/01/archives/the-fidelistas-of-brazil.html. Acesso em: Acesso em: 26 ago. 2019.

OLIVEIRA, Francisco de. Elegia para uma re(li)gião: SUDENE, Nordeste. Planejamento e conflito de classes. $3^{a}$ ed. Rio de Janeiro, Paz e Terra, 1981.

RAPOPORT, Mario; LAUFER, Rubén. Os Estados Unidos diante do Brasil e da Argentina: os golpes militares da década de 1960. Rev. bras. polít. int., Brasília, v. 43, n. 1, p. 69-98, 2000.

SILVA, David Fernando Nogueira da. A "revolução das esperanças crescentes": Adlai Stevenson, a Teoria da Modernização e a Guerra Fria na América Latina. Tese (Doutorado em História)-Universidade de Brasília, Brasília, 2018.

SOUZA, Fábio de. $O$ Movimento de Cultura Popular do Recife (1959-1964). Dissertação (Mestrado em História Social), Faculdade de Filosofia, Letras e Ciências Humanas, Universidade de São Paulo, São Paulo, 2014.

SZULC, Tad. Northeast Brazil Poverty Breeds Threat of a Revolt. New York Times, Nova York, 31 out. 1960a. Disponível em: https://www.nytimes.com/1960/10/31/archives/northeast-brazil-poverty-breeds-threat-of-a-revoltbrazils-poverty.html. Acesso em: 26 ago. 2019.

.Marxists are Organizing Peasants in Brazil. New York Times, Nova York, 1 nov. 1960b. Disponível em: https:// www.nytimes.com/1960/11/01/archives/marxists-are-organizing-peasants-in-brazil-leftist-league-aims-at-a. html. Acesso em: 26 ago. 2019. 